\title{
A Framework for Maintaining Socio-technical Balance during the Evolution of Complex Systems
}

\author{
Igor Hawryszkiewycz \\ School of Systems, Management and Leadership \\ University of Technology, Australia \\ igorhait.uts.edu.au
}

\begin{abstract}
Distributed systems are growing increasingly complex in the sense that they need to reorganize on a regular basis to respond to external opportunities. At the same time research has shown that performance is improved where technology support is aligned to people's activities within the system. This paper provides a framework for ensuring that such alignment is maintained during system evolution. The paper first defines the nature of change using complexity theory as the foundation for defining the nature of change. It then builds on the idea of socio-technical gaps to identify the gaps created by a change. The changes are then outlined in terms of perspectives to provide a systematic basis for managing change. To do this change is expressed in terms of the perspectives to provide a meaningful way to respond to change.
\end{abstract}

Keywords: Complexity theory, System evolution, Social factors.

\section{Introduction}

Business trends as outlined by McAfee [1] are towards what is called Enterprise 2.0, which focuses on obtaining competitive advantage through networking and collaboration. This when combined with Web 2.0 provides the infrastructure for a more collaborative business environment. Typical developments here are process ecosystems [2], where process owners create independent processes, a service oriented environment where systems must continually respond to changing customer needs; greater client involvement in design as described by Cova and Salle [3], and new forms of collaborative supply chains, where services are negotiated jointly at each interface during the operation of the supply chain. Rye [4] proposes that knowledge be shared at each supply chain transition to continually adjust the process as requirements change.

These systems are dynamic in nature and differ from the predominantly deterministic systems. Many design processes, however, still use methods that support deterministic processes. This paper focuses on ways to design dynamic systems. It proposes that complexity theory can provide a systematic way to support evolution. It also has the additional goal of ensuring that any change is implemented in ways that maintain system balance during the change. The paper follows the approach shown in Figure 1 and described following: 
- The paper first describes the socio-technical framework that provides a systematic method for identifying imbalances in a system and ways to identify and correct any imbalances that may arise during system evolution.

- This is followed by an outline of complexity theory and the criteria it provides to information system design especially as a way of defining system evolution in terms of a complete set of change

- The paper then describes a way to manage complexity by describing systems from different perspectives,

- The paper then provides a way to identify the potential impact of change or evolution in terms of different perspectives, in particular, the business activity, the social network and the knowledge flows.

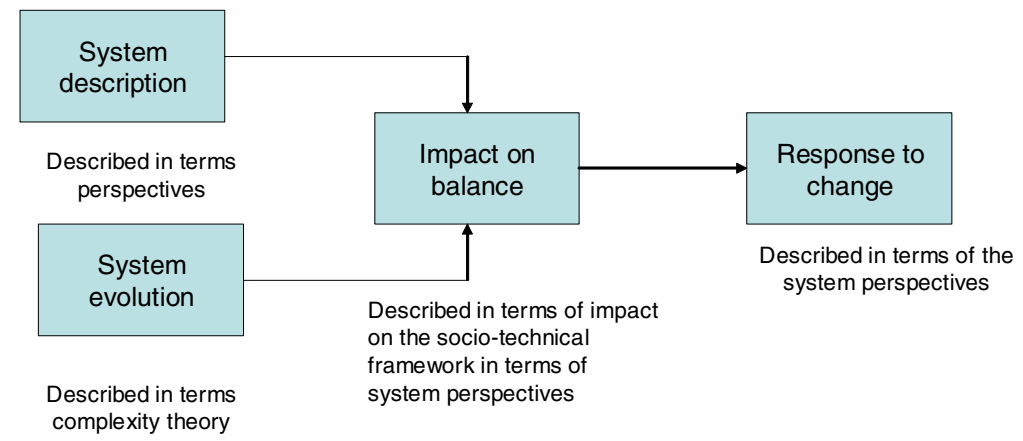

Fig. 1. Managing Change

\section{Socio-technical Framework}

This paper uses the idea of gaps based on the structure introduced by Leavitt [5] and illustrated in Figure 2.

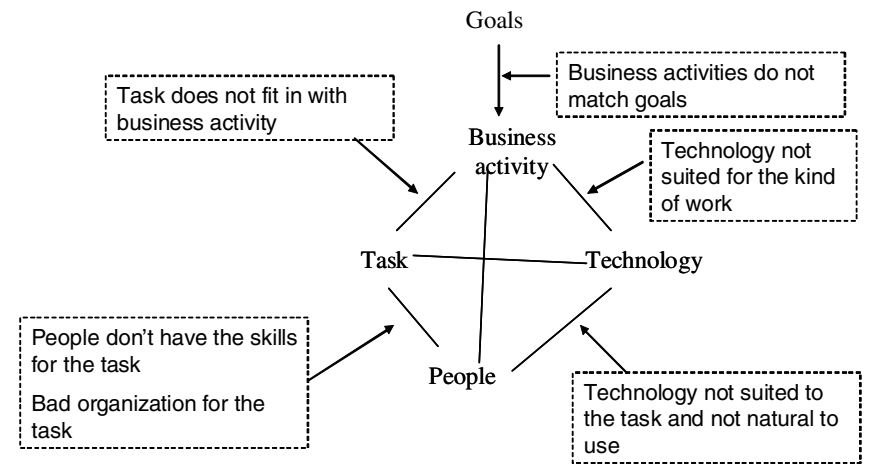

Fig. 2. Defining socio-technical gaps 
Figure 2 shows the major concepts that make up a system, namely, business activity, task, people and technology. The system is driven by goals and business activities must be designed to realize the goals. The goal of design is to have the concepts designed in such a way that there are no "gaps" in system operation. Thus business activities must be chosen to realize the goals. Other gaps may be that the people are assigned to tasks without necessary skills needed for the task; or that the technology does not match people's work practices.

\section{Defining Criteria of Change from Complexity Theory}

Knowledge workers should be able to quickly comprehend how to adopt any new technology, and assimilate it in their work [6]. The suggestion here is that IS system design no longer focus on the design of deterministic systems that attempt to reduce complexity through structure but on systems that support evolution and change. The paper suggests that the foundation for such systems comes from complexity theory.

There is now an emerging body of knowledge that sees close correspondence to complexity theory and the emerging information system environment. The major contribution is to use complexity theory to define a generic framework for system evolution and then show that a number of perspectives are needed to address evolution in a systematic manner. It draws on work such as that of Merali [7] or McElroy [8], who see information systems now becoming more complex and suggest that designers draw on the principles of complex systems when designing new information systems. This implies a change of emphasis in design. Instead of top down development of systems that follow predefined processes, what are now needed are systems that support change. McElroy describes this as a change from complexity reduction through the top-down creation of deterministic systems to designing systems that are designed to support change. The paper introduces the idea of perspectives that can be used to respond to change.

\section{System Perspectives}

Managing system evolution requires cognitive abilities to understand the impact of change on different system components. The proposal here is to view components of information systems as different perspectives that go across functions. Such perspectives are system wide rather than focused on each individual functions thus providing a holistic view of change. In summary, the perspectives proposed here are:

- The business activities and their actions and outcomes,

- The process workflow or sequence of activities and the interdependence between activities,

- The social structure, which is seen as a critical element (Pralahad and Krishnan, 2008), that describes roles and their responsibilities and the assignment of roles to individuals and the relationships between them. This is critical in the design of the collaborative infrastructure as it defines the specific collaboration

- The knowledge created and used during the activities, 
- The organizational perspective in the kinds of teams support or leadership provided to support collaboration and innovation,

- The technology to support the collaboration, which is needed to share and create knowledge.

Another view of perspectives is as components of an information system. A working system should maintain good working relationships between these components.

\section{System Evolution expressed in Terms of Perspectives}

The structural dimensions are derived from the foundation to provide a meaningful way to talk about change in terms understood by system designers. These include:

Table 1. Structure change and perspectives

\begin{tabular}{|l|l|}
\hline Structural Change & Effect on perspectives \\
\hline $\begin{array}{l}\text { Ability to self-organize at local levels in } \\
\text { response to wide variety of external } \\
\text { change. }\end{array}$ & $\begin{array}{l}\text { This kind of results in an impact social } \\
\text { structure in terms of business activities. } \\
\text { It often requires new viewpoints on } \\
\text { decision making by bringing in new } \\
\text { expertise and the need for new } \\
\text { knowledge from existing systems. }\end{array}$ \\
\hline $\begin{array}{l}\text { Quick establishment of self-contained } \\
\text { units that address w ell-defined parts of } \\
\text { the environment. }\end{array}$ & $\begin{array}{l}\text { This often implies the creation of a new } \\
\text { business activity. This in turn calls for } \\
\text { new responsibilities and resulting } \\
\text { changes to the social structure. }\end{array}$ \\
\hline $\begin{array}{l}\text { Loose connections between system } \\
\text { elements and a way to reorganize the } \\
\text { structure to respond to external change. }\end{array}$ & $\begin{array}{l}\text { This often requires the injection of an } \\
\text { innovative social structure to maintain } \\
\text { brokering arrangements between } \\
\text { existing processes. }\end{array}$ \\
\hline $\begin{array}{l}\text { Ability to organize connections into } \\
\text { larger components with consequent } \\
\text { changes to connections and interactivity }\end{array}$ & $\begin{array}{l}\text { The initial impact here is on social } \\
\text { structure and knowledge requirements. } \\
\text { Generally access to knowledge is } \\
\text { provided to a wider set of activities } \\
\text { although the activities themselves do } \\
\text { not change. }\end{array}$ \\
\hline $\begin{array}{l}\text { Aggregation of smaller units into larger } \\
\text { components }\end{array}$ & $\begin{array}{l}\text { The initial impact here is on social } \\
\text { structure and knowledge requirements. } \\
\text { It generally requires a consolidation of } \\
\text { knowledge requirements and providing } \\
\text { access to a wider set of roles. }\end{array}$ \\
\hline
\end{tabular}




\section{Combining Perspectives and the Socio-technical Framework}

Change can then be expressed by identifying the primary reason for the change and then following through the links in the socio-technical framework in terms of the perspectives. For example a change of goal can be seen to first impact on the business activity, then on the tasks, the people and social structures needed and the technology. The relationships between perspectives shown in Figure 3 provide the necessary rules for mapping between the perspectives. For example:

Change of goal $\rightarrow$ Impact on business activity $\rightarrow$ change in task --.> change of social structure $\rightarrow$ change in technology.

These changes are then expressed in terms of the perspectives. Often as shown in Figure 5 a different perspective can be used in reducing each gap.

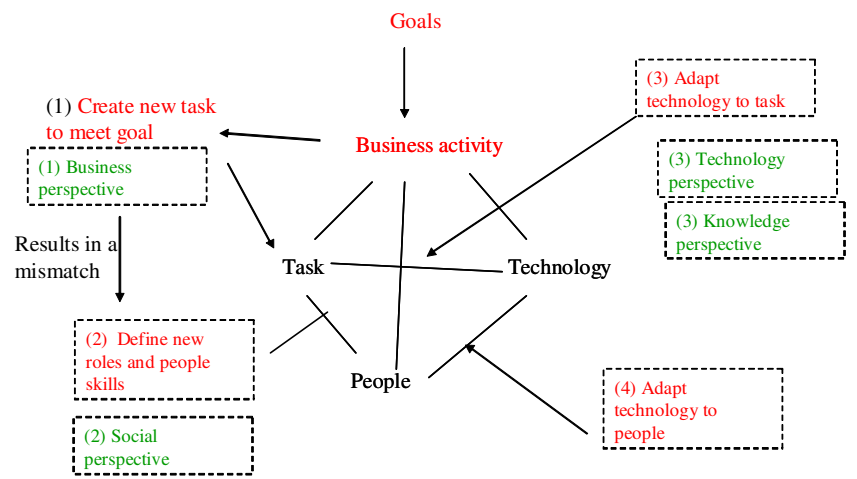

Fig. 3. Mapping change to the socio-technical framework

Support for such can be provided through agents. To do this requires some guidelines and rules that can be used by agents to support evolution. These guidelines must express the relationships ion Figure 3 in more detail. Typical rules can be

- A change in business activity where a new expert opinion is needed result is a social change where a new innovative social structure is inserted into an activity.

- A problem has arisen in a supply chain requires the creation of a new team structure linked to an existing activity as for example [9] system problems that require a software provider to resolve software issues in a service provision.

\section{The Architecture for Alignment}

One question not addressed so far is who manages system changes to respond to the evolution in the business environment. The standard approach has been for 
information technology (IT) specialists to implement changes to supporting technologies. In the more dynamic environments now found in industry the response times may not be adequate.

The paper suggests the architectural structure shown in Figure 4. It separates the more traditional applications based on ERP systems from the more dynamic requirements of knowledge workers. The analytical work support requires support for creation new social structures and providing them with abilities to access information in the ERP systems.

Workspaces for the more analytical work should provide the ability to change the social structure as new knowledge needs arise or new business relationships are established. Workspaces can contain commands that can be used to make the kind of changes described in Table 1. The goal is to extend workspaces by providing supporting agent use the relationships described in Figure 3 to guide users through making these changes.

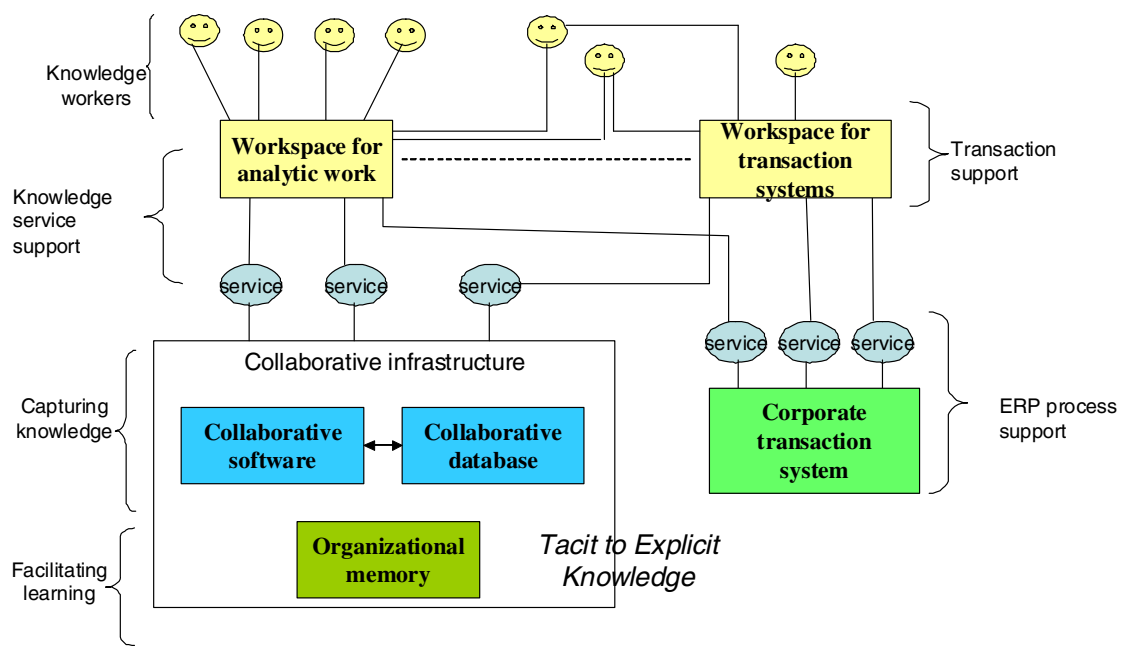

Fig. 4. Combining explicit and tacit

\section{Summary}

The paper proposed a systematic way of managing change within evolving information systems. It combined the idea of change as defined by complexity theory with a socio-technical framework using the idea of system perspectives. Change was described in terms of the perspectives, which then indicated a systematic way of adjusting other perspectives. Future work is focusing on defining the relationships between perspectives in more detail with the goal of identifying ways to assist knowledge workers to change the system themselves. 


\section{References}

1. McAfee, A.P.: Enterprise 2.0: The Dawn of Emergent Collaboration. MIT Sloan Management Review, 21-28 (2006)

2. Vidgen, R., Wang, X.: From business process management to business process ecosystem. Journal of Information Technology 21, 262-271 (2006)

3. Cova, B., Salle, R.: Marketing solutions in accordance with S-D logic: Co-creating value with customer network actors. Industrial Marketing Management 37, 270-277 (2008)

4. Rye, K., Lee, S., Choi, H.: Modularization of web-based collaboration systems for manufacturing Innovation. In: Proceedings of the Tenth International Conference on Enterprise Information systems, Barcelona, June 12-16, pp. 174-177 (2008)

5. Leavitt, H.J.: Applied Organizational Change in Industry: Structural, technical and humanistic approaches. In: March, J.G. (ed.) Handbook of Organization, pp. 1144-1170. Rand-McNally, Chicago (1965)

6. Davenport, T.: Thinking for a Living. Harvard Business School Press, Boston (2005)

7. Merali, J.: Complexity and Information Systems: the emergent domain. Journal of Information Technology 21(4), 216-233 (2006)

8. McElroy, M.W.: Integrating Complexity theory, knowledge management and organizational learning. Journal of Knowledge Management 4(3), 195-203 (2000)

9. Hawryszkiewycz, I.T.: Lightweight Technologies for Knowledge Based Collaborative Applications. In: Proceedings of the IEEE CEC/EEE2007 Conference on E-Commerce Technology, Tokyo, pp. 255-264 (July 2007) 